\title{
Blumenberg, Izutsu y la experiencia ante la nada
}

\section{Blumenberg, Izutsu and the Experience of the Nothing}

\author{
César GonzÁlez CANTÓN \\ CUNEF (Colegio Universitario de Estudios Financieros, UCM) \\ cgcanton@gmail.com
}

Recibido: 18/01/2015

Aceptado: 24/06/2015

\section{Resumen}

Este trabajo interpreta la idea de Apocalipsis en clave ontológica, esto es, como experiencia de la nada. Existe una diferencia fundamental entre las narrativas de Blumenberg e Izutsu acerca de esta experiencia. El primero considera que en ella no se accede más que a una situación de absoluta vulnerabilidad y pérdida de referencias, que es rápidamente subsanada - el Apocalipsis no es nunca definitivo y pasa pronto. Izutsu, por el contrario, argumenta que cabe una experiencia real de la contingencia, en la que el mundo y la conciencia adquieren unas características específicas. Para Izutsu, el Apocalipsis da lugar, realmente, a "un cielo nuevo y una tierra nueva" (Apocalipsis 21:1).

Palabras clave: Nada, apocalipsis, contingencia, Budismo zen, conciencia

\begin{abstract}
This work presents an ontological reading of the idea of Apocalypse, i.e., as the experience of the Nothing. Blumenberg's and Izutsu's narrative accounts are very different in this respect. The former claims that the Nothing is experienced through absolute vulnerability and the of references. However, this experience is rapidly taken care of and does not last long: The Apocalypse never becomes a definitive state of being. The latter, on the contrary, argues that the experience of contingency can be so real as to unveil world's and consciousness's specific features. Izutsu affirms that the Apocalypse truly gives way to "a new Heaven and a new Earth" (Apocalypse 21:1).

Keywords: Nothing, apocalypse, contingency, Zen Buddhism, consciousness
\end{abstract}




\section{Metafísica occidental y cosmos}

En este apartado presentaré las comprensiones de Izutsu y Blumenberg, coincidentes en gran medida, sobre la noción griega de cosmos y la metafísica occidental. En las siguientes secciones abordaré dónde se separan, esto es, en su tratamiento de la contigencia.

Por resultar probablemente menos familiar que Blumenberg, damos aquí un breve apunte biográfico y filosófico de Toshihiko Izutsu. Este filósofo japonés (4 Mayo 1914 - 7 Enero 1993), gran estudioso del Islam y, en general, del fenómeno religioso desde una perspectiva comparada. Desempeñó su labor docente e investigadora, entre otros lugares, en Irán y Canadá. Primer traductor del Corán al japonés, adquirió una gran reputación como buen conocedor de la filosofía y teología islámicas en sus correrías académicas por el Medio Oriente. Sus trabajos más importantes son $\mathrm{Su}$ fism and Taoism: A Comparative Study of Key Philosophical Concepts (1983) y una colección de ensayos, publicada póstumamente, titulada Creation and the Timeless Order of Things (1994). El trabajo de Izutsu puede encuadrarse en una filosofía de la contingencia: no del Ser, sino de la no-existencia.

En este artículo vamos a tratar, sobre todo, con su obra Bewusstsein und Wesen (1983). En este libro examina lo que pensadores occidentales - tales como Sartre, Husserl, Heidegger, Mallarmé- -han dicho sobre la experiencia de la nada. Izutsu está convencido de que el sufismo islámico, la kabbala hebrea, el Zen esotérico, algunos compositores de haiku y otros ejemplos orientales han alcanzado una imagen del conocimiento y la realidad más ajustada que las de sus contrapartidas occidentales.

Para entender la propuesta de Izutsu, es necesario conocer su descripción de los elementos básicos de la tradición platónico-aristotélica, en la que, por otra parte, coincide en gran medida con los análisis de Heidegger y Blumenberg.

En primer lugar, la realidad tiene una estructura. Hay cosas que existen en el tiempo, que, como troncos flotando en un rio, aparecen y desaparecen. La conciencia también se percibe a sí misma como una corriente temporal donde, de vez en cuando, las cosas aparecen a través de los canales de la percepción, las emociones, los pensamientos, etc ${ }^{1}$. Izutsu asume la caracterización husserliana de la conciencia ${ }^{2}$, como también lo hace Blumenberg ${ }^{3}$.

En segundo lugar, lo que una cosa "es" es su "esencia"-el einai aristotélico, la essentia del Aquinate o la mahiya islámica. La esencia es universal y eterna, y se opone a la particularidad (hiyuwa) de las cosas que aparecen y desaparecen en el

\footnotetext{
${ }^{1}$ T. Izutsu, Bewusstsein und Wesen, Munich, Iudicium Verlag, 1983, pp. 74-75.

${ }^{2}$ E. Husserl, "Zur Phänomenologie des inneren Zeitbewusstesens (1893-1917)", en R. Boehm (ed.), Husserliana Vol. X, The Hague, Netherlands, Martinus Nijhoff, 1969, p. XXXIII.

${ }^{3}$ H. Blumenberg, Lebenszeit und Weltzeit, Frankfurt am Main, Suhrkamp, 1986.
} 
tiempo. La oposición entre mahiya y hiyuwa es característica de esta visión de la realidad. Cada polo de la dicotomía ha tenido sus defensores, aquellos que consideran la esencia como la "verdadera" realidad de las cosas (Platón, Husserl, Mallarmé) frente a aquellos que conceden el máximo grado de realidad a la cosa particular (Ockam, Rilke).

En tercer lugar, la realidad aparece como objeto frente al sujeto. Ambas son realidades heterogéneas. El tipo de conocimiento adecuado a las esencias es de tipo teórico, aunque también se perciban a través de emociones, creencias y opiniones, y la manipulación de objetos ${ }^{4}$, donde la separación de sujeto y objeto es menos marcada. Descartes y Husserl pueden considerarse el culmen de la actitud teorética.

Por su parte, Blumenberg entiende que la concepción de la realidad platónicoaristotélica ha quedado recogida en la noción de "cosmos", "el ideal del ser"s, el cual equivale a un mundo no histórico. La doctrina aristotélica de la sustancia es fruto de esta concepción.

La inestabilidad constitutiva del hombre le lleva a atribuir a la realidad dos propiedades, opuestas a la historicidad, fundamentales en la noción de cosmos. Por un lado, la de estar estructurado jerárquicamente, tener un orden y una legalidad, que es lo que significa literalmente "cosmos". Por otro, la de que ese orden sea intangible, que es otro modo de denominar su necesidad y estar fuera del tiempo.

El cosmos es considerado con el hombre. Le manda "mensajes" sobre su origen, destino, estructura de la realidad y modo de conducta. Es lo que se ha denominado teleología. Nietzsche -para quien esta noción es la esencia del cosmos- la describe como aquel concepto que permite entender los procesos naturales como "acciones" 6 en favor del hombre. En el ámbito material, puede significar, por ejemplo, que la realidad "da de comer al hombre". En el ámbito del conocimiento, significa que la realidad, en su forma ideal, aparece como evidencia, es decir, como una realidad que se entrega inmediatamente a la razón. Ya sea en su aspecto racional o físico, la teleología representa el acompasamiento del tiempo de la vida y del tiempo del mundo. En este sentido, una de las formulaciones principales del principio teleológico es "el principio del sentido más antiguo: que nada ocurre en vano ${ }^{7}$ y que nada se pierde"

\footnotetext{
${ }^{4}$ Izutsu, op. cit., p. 11.

${ }^{5} \mathrm{H}$. Blumenberg, Die ontologische Distanz. Eine Untersuchung über die Krisis der Phänomenologie Husserls, Kiel, Christian-Albrecht Kiel Universität, 1950, p. 52.

${ }^{6} \mathrm{H}$. Blumenberg, "Ordnungsschwund und Selbstbehauptung. Über Weltverstehen und Weltverhalten im Werden der technischen Epoche", en H. Kuhn y F. Wiedmann (eds.), Das Problem der Ordnung. VI Deutscher Kongress für Philosophie. München, Meisenhelm am Glan, Ham, 1962, pp. 37-57, aquí p. 38 .

${ }^{7}$ Se refiere aquí Blumenberg al principio aristotélico de que la naturaleza no hace nada en vano.

${ }^{8}$ H. Blumenberg, Die Lesbarkeit der Welt, Frankfurt am Main, Suhrkamp, 1981, p. 375.
} 
A continuación vemos cómo, a partir de una comunidad de entendimiento en la cuestión del cosmos, divergen estos dos autores cuando se enfrentan a la experiencia de la contingencia.

\section{Blumenberg, o el "No se preocupen, el Apocalipsis pasará pronto"}

Blumenberg lleva a cabo una fundamentación antropológica de los grandes temas de la metafísica clásica, sobre todo tal y como se encuentran adoptados en el pensamiento de Husserl y Heidegger. A este respecto es de gran importancia el trabajo de Blumenberg sobre la famosa discusión de Davos entre Heidegger y Cassirer ${ }^{9}$, en la que éste último opone a la analítica del Dasein una antropología filosófica.

Blumenberg quiere analizar la vida humana como productora de sentido donde no lo hay. Esta producción es una huida de la experiencia de la finitud (que Blumenberg llama Inständigkeit) hacia la condición usual de nuestra existencia, la de la significatividad. En oposición a Heidegger, la Gegenständigkeit pertenece al ámbito de la significatividad, porque la significatividad es lo contrario de la experiencia de la contingencia.

La Inständigkeit es un concepto límite, que, al contrario que en Heidegger, nunca se da de modo puro y como tal, porque cualquier intento de comprenderla es ya una establecimiento en ella de "señales", una objetivación ${ }^{10}$. Lo que es la situación del man para Heidegger es para Blumenberg el modo auténtico de la existencia del Dasein. 'La 'pasión ['Leidenschaft']' de la facticidad, del presente originario, no es permanente; es ya movimiento hacia la Gegenständigkeit y, al mismo tiempo, el fundamento de ese movimiento" 11 . Para Blumenberg, de que ser histórico sea estar ya en la pregunta, "se sigue [...] que, en y antes de cualquier pregunta que el Dasein pueda plantear, tiene ya que dar una 'respuesta [Antwortung]', que su existencia [Dasein] es 'responsabilidad [Verantwortung]"'12. La vida siempre se desarrolla ya en Gegenständigkeit, que es "el mismo modo en que se lleva a cabo esa «respuesta» originaria, que está dada en el estar-en-la-pregunta del Dasein"13. Tanto como en la Entschiedenheit, el Dasein vive ya en la interpretación (Ausgelegtheit).

La relación entre Inständigkeit y Gegenständigkeit es, así, más compleja de cómo la había visto Heidegger: "la ontología de la esencia y la ontología de la existencia

\footnotetext{
${ }^{9}$ H. Blumenberg, "Ernst Cassirers gedenkend bei der Entgegennahme des Kuno-Fischer Preises der Universität Heidelberg im Juli 1974", en Wirklichkeiten in denen wir leben. Aufsätze und eine Rede, Stuttgart, Reclam, 1981, pp. 163-172.

${ }^{10} \mathrm{H}$. Blumenberg, Beiträge zum Problem der Ursprünglichkeit der mittelalterlich-scholastischen Ontologie, Kiel, Kiel Universität, 1947, p. 65. Esto se ve en que cualquier experiencia de la finitud se mueve dentro de unas determinadas categorías como, por ejemplo, la de la idea de creación de la nada.

${ }^{11}$ H. Blumenberg, Die ontologische Distanz, op. cit., p. 125.

${ }^{12}$ Ibidem, p. 110.

${ }^{13}$ Ibidem, p. 120.
} 
heideggerianas están fundidas en los 'términos' de la distancia ontológica, pero no conforman una categoría suficiente para comprender estas posiciones ontológicas extremas, ni en su oposición ni en su unidad"14.

"En su unidad", porque tanto en la Inständigkeit como en la Gegenständigkeit se da esa separación del ser. La "distancia ontológica" no se da sólo en la Gegenständigkeit -entendida como relación sujeto-objeto ${ }^{15}$-, sino también en la Inständigkeit. En la experiencia de la finitud, el ser aparece como "lo extraño (Fremdheit)"; en la significatividad, tenemos que vérnoslas con las estructuras creadas precisamente para evitar esa experiencia.

"En su oposición" indica que ninguno de los polos se deja resolver a favor del otro $^{16}$, como ocurre en Heidegger, para quien la tarea ontológica es la deconstrucción de la Gegenständigkeit, proceso en que se realiza la plenitud del Dasein. Frente al Abgrund heideggeriano, la vida busca un suelo (Grund) sobre el que poder desarrollarse ${ }^{17}$; la deconstrucción heideggeriana es, en último término, una destrucción de aquello en lo que el hombre puede desarrollar su vida, el mundo. Al mismo tiempo, la experiencia de la finitud está siempre presente, pues la misma vida se coloca en situaciones de contingencia.

Así, en los términos del presente trabajo, Heidegger sería representante de una filosofía apocalíptica, para la que el Dasein encuentra plenitud en la destrucción del mundo. Por el contrario, Blumenberg vería el apocalipsis como una situación recurrente y nunca definitiva. Esto se ve aún más claro si, como se verá a continuación, se explicita aún más que el polo de la Gegenständigkeit no es más la construcción de un mundo habitable por el hombre. De este modo, el paralelismo con la narrativa del mundo y su fin es aún más claro.

El movimiento ontológico constituye la historicidad ${ }^{18}$, tanto en la vida individual la "historia de mi vida"- como en la de la humanidad, cuyo relato conforma la Historia con mayúsculas. Para Blumenberg, las categorías de la distancia ontológica tienen que acreditar su "adecuación ontológica" 19 en el horizonte más amplio de la historia de la humanidad. En la línea de la ontología hermenéutica de Heidegger, el filósofo es para Blumenberg siempre, en un sentido profundo, historiador de la filosofía.

Blumenberg utiliza para ello el instrumento de la "imagen del mundo (Weltbild)", que es la estructura significativa más global de la Gegenständigkeit, y equivale a lo que se puede llamar "visión del mundo", "época", "espíritu de una época", y conceptos similares. La imagen del mundo es lo que se construye para tapar la Inständigkeit y todo el ser al que se puede acceder, ya que en la experiencia de la contingencia

\footnotetext{
${ }^{14}$ Ibidem, pp. 10c-10d.

${ }^{15}$ Ibidem, p. $10 \mathrm{c}$.

${ }^{16}$ Ibidem, p. 120.

${ }^{17}$ H. Blumenberg, Begriffe in Geschichten, Frankfurt am Main, Suhrkamp, 1998, p. 75.

${ }^{18}$ H. Blumenberg, Die ontologische Distanz, op. cit., p. 121.

${ }^{19}$ Ibidem, pp. 7-8.
} 
nunca se accede al ser en sí mismo. Para eliminar cualquier sugerencia de que haya un conocimiento del ser, Blumenberg sustituye la "comprensión del ser (Seinsverständnis)" heideggeriana por la expresión "concepción de la realidad (Wirklichkeitsbegriff)" o "imagen del mundo (Weltbild)". El objeto de la ontología pasa del "ser" o "realidad", que no podemos conocer, al "mundo" o, mejor dicho, a los "mundos", que es el conjunto de lo que el Dasein hace una vez y otra contra la finitud.

Blumenberg distingue -"no sin simplificación"20, advierte- tres concepciones básicas de la realidad, cuya sucesión constituiría la historia de la humanidad: época antigüedad, medieval y moderna. Lo que provoca para Blumenberg una nueva imagen del mundo - $\mathrm{o}$ un cambio significativo dentro de una de ellas- es una determinada experiencia, diferente en cada caso, de la contingencia. Ante ella, cada época desarrolla estrategias para seguir afirmando el sentido, hasta que se hace precisa una nueva visión del mundo. El paso de la visión antigua a la medieval viene recogido en la idea de Creación de la nada; el paso a la edad moderna, en el desvalimiento ante el Dios nominalista. La Ilustración es, en la Modernidad, el intento de ocultar la historicidad del ser, que aparecería inapelable ${ }^{21}$ tras la Primera Guerra Mundial. Cada uno de estos cambios epocales representa la oposición de la Gegenständigkeit a la Inständigkeit. La clave interpretativa de la existencia y de la historia humanas va a ser, para Blumenberg, el proceso por el cual el hombre una y otra vez se "descarga de absolutos (Entlastung von Absoluten)", como ha descrito Odo Marquard ${ }^{22}$; esto es, el proceso por el cual va tomando distancia de la "Übermächtigkeit" de la contingencia. Es lo que Blumenberg llama autoafirmación (Selbstbehauptung).

El recorrido histórico por las concepciones de la realidad no es, por tanto, "una tarea obligada por la práctica filosófica, sino un elemento fundamental y necesario de la investigación misma"23. Blumenberg, siguiendo a Heidegger, lleva a cabo una "destrucción (Destruktion)" histórica de los modos en que la experiencia del ser ha quedado oculta bajo una determinada "comprensión"; el objeto de la destrucción no es llegar al ser, sino a la existencia humana: una ontología de la lucha contra la contingencia que constituye la Historia o, lo que es lo mismo, una antropología hermenéutica.

\footnotetext{
${ }^{20}$ H. Blumenberg, "Paradigmen zu einer Metaphorologie", en Archiv für Begriffsgeschichte 6 (1), 1960, pp. 7-142, aquí 38 .

${ }^{21}$ Aunque eso no quiere decir que no haya siempre intentos -en todas las épocas- de esconder la contingencia, ya que, como hemos dicho, ninguno de los polos de la distancia ontológica puede resolverse a favor del otro.

${ }^{22}$ O. Marquard, "Hans Blumenberg. Entlastung vom Absoluten", en F. J. Wetz y H. Timm (eds.), Die Kunst des Überlebens, Frankfurt a.M., Suhrkamp, 1999, pp. 7-16, aquí p. 21. Como cuenta él mismo, Marquard le preguntó a Blumenberg en el marco de un congreso si le molestaba que redujese su filosofía a dos ideas básicas: aquella de la finitud del hombre con su contrapartida, el carácter insoportable de cualquier absoluto; y aquella de que ser hombre consiste en "descargarse de los absolutos". Con gran elegancia, Blumenberg le respondió: "Lo que me molesta es que sea tan fácil verlo", O. Marquard, op. cit., p. 21.

${ }^{23}$ H. Blumenberg, Die ontologische Distanz, op. cit., p. 36.
} 
Lo específico de Blumenberg es, como veremos, que esa destrucción de los conceptos de cada imagen del mundo se realiza al hilo de ciertas imágenes fundamentales -"metáforas absolutas"- subyacentes a esos conceptos. Las metáforas absolutas son, precisamente, en lo que consiste la "imagen" del mundo.

El uso de metáforas es una consecuencia directa de su giro a la antropología, en el sentido en que la antropología filosófica ha conferido al símbolo una importancia fundamental para entender al hombre. La antropología hermenéutica de Blumenberg es, por ello, una metaforología.

En términos apocalípticos, Blumenberg está afirmando que, en realidad, nunca pasa nada. No puede haber, como hemos dicho arriba, experiencia de la contingencia pura, ni da tiempo a ver qué queda revelado por el Apocalipsis (el Ser, Dios, etc.), pues la construcción de un nuevo mundo es simultánea.

\section{Izutsu: "Un cielo nuevo y una tierra nueva"}

La descripción blumenberguiana de la contingencia está en la línea de las que Izutsu encuentra en el Ser de Heidegger o "la Nada" de Sartre, así como en la doctrina del budismo Zen. La natural reacción ante ella es la náusea, la reacción animal a lo que Blumenberg había visualizado como falta de orientación.

Para Izutsu, esta descripción es fundamentalmente correcta. Sin embargo, el error estaría en pensar, como hace Blumenberg, que esta es la última palabra de lo que se puede decir sobre el Ser. Cabe una verdadera experiencia del Ser más allá de la metafísica clásica y de la Nada sartriana.

En realidad, el conocimiento del Ser soporta nuestra conciencia ordinaria de las diferentes cosas y eventos que percibimos ${ }^{24}$. Se trata de un conocimiento "casi instintivo [...] incluso prerreflexivo, inconsciente o bajo la forma de una comprensión al modo sentimental’25. El siguiente gráfico servirá para explicar la posición de Izutsu:

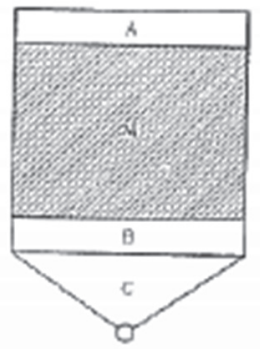

Fuente: Izutsu' ${ }^{26}$.

\footnotetext{
${ }^{24}$ T. Izutsu, Bewusstsein und Wesen, op. cit., p. 10.

${ }^{25}$ Ibidem, p. 11.

${ }^{26}$ Ibidem, p. 191.
} 
"A" corresponde a la razón teórica en sentido aristotélico y, en general, el propio de la tradición racionalista occidental que hace distinción entre sujeto y objeto en el conocimiento.

"M" es el nivel de la imaginación. A él llega el conocimiento del ser a través de las imágenes arquetípicas del nivel B, lo cual explica la importancia de las metáforas para el conocimiento. En relación con el papel de las metáforas en la metafísica islámica, Izutsu dice que "el uso frecuente de metáforas en la metafísica es una de las marcas características de la filosofía islámica, o debiera decir de la filosofía oriental en general. No se deben tomar por ornamentos poéticos. Su uso está asociado claramente a una función cognitiva" ${ }^{27}$, que proviene del contacto de la conciencia con el Ser en el nivel C.

"B" es, según Izutsu, el nivel de lo que Jung llamó "el inconsciente", el lugar de los "arquetipos". Como explica Jung, estos no son imágenes particulares de nada sino "una tendencia a formar representaciones de un motivo" 28 . Por este motivo, sobreviven en la mente colectiva de la humanidad edad tras edad.

"C" es la parte inferior de la mente humana. Para Izutsu, está en contacto con la verdadera naturaleza de la realidad. Al contrario que el nous aristotélico, el inconsciente está profundamente imbuido en los dinamismos biológicos y corporales. Así , el acceso al ser solo puede alcanzarse abandonando el estado "natural" o consciente de la mente, esto es, a través de un entrenamiento específico en técnicas Zen o sufíes.

En este nivel, las cosas no son lo que son; no hay tal cosa como "las cosas". Como afirma el budismo zen, la multiplicidad es falsa ${ }^{29}$. No hay esencias sino el Ser, que resulta ser lo mismo que "la Nada". En consecuencia, la dialéctica sustituye la validez ontológica y lógica del principio de no contradicción. Todo puede ser todo.

Esa es la razón por la que nada puede predicarse de nada. La doctrina Zen del no diálogo es un intento sistemático de romper la lógica proposicional característica de la metafísica occidental: para cualquier pregunta, cualquier respuesta es buena. Incluso, cuanto menos relacionadas estén, más claramente se verá que la realidad ha dejado de estar estructurada por el lenguaje $\mathrm{e}^{30}$. Las palabras ya no captan la esencia de la realidad.

Finalmente, ha desaparecido la dicotomía de sujeto y objeto, lo cual conduce a su fusión en una unidad en la que no hay discriminación ${ }^{31}$.

\footnotetext{
${ }^{27}$ T. Izutsu, "The basic structure of metaphysical thinking in Islam", en M. Mohaghghegh y H. Landolt (eds.), Collected Papers on Islamic Philosophy and Mysticism, Teheran, 1971, pp. 39-72.

${ }^{28}$ C. G. Jung, M.-L. von Franz, J. L. Henderson, J. Jacobi y A. Jaffé, Approaching the unconscious, Man and his Symbols, London, Picador, 1965, pp. 2-94, aquí p. 58.

${ }^{29} \mathrm{~T}$. Izutsu, Bewusstsein und Wesen, op. cit.

${ }^{30}$ Ibidem, pp. 319 y s.

${ }^{31}$ K. Nakamura, "The Significance of Toshihiko Izutsu's Legacy for Comparative Religion”, en Intellectual Discourse 17(2), 2009, pp. 147-158, aquí p. 152.
} 
Para Izutsu, en este punto es donde se detienen el existencialismo y, en general, las corrientes occidentales críticas de la metafísica occidental y el budismo Zen, que define la experiencia de "la Nada" como la verdadera naturaleza de la realidad. Izutsu, por el contrario, piensa que el budismo esotérico, el sufismo islámico y otras fuentes se caracterizan por proponer lo que llama "el cambio de sentido (U-turn) del proceso de conocimiento" 32 . Se trata de una re-articulación de la realidad. El proceso descrito hasta el momento - de la actitud "natural" a la experiencia de la nada - sería el primer brazo de la U. Una vez ocurrida la desarticulación descrita en "C", el proceso de conocimiento cambia de sentido y se dirige de nuevo a la realidad "normal", pero sometiéndola a una re-articulación (el segundo brazo de la U).

En esta etapa final la realidad aparece estructurada otra vez. Las cosas son lo que son tras haber recuperado sus esencias particulares, pero ahora el Ser universal puede ser percibido en lo particular. Como consecuencia, el mundo de las cosas puede verse bajo la perspectiva de la eternidad sin perder su carácter temporal ${ }^{33}$. Cada cosa está unida a las demás pero formando un todo coherente, dando lugar a una visión holística a partir de cada cosa particular.

La dialéctica sigue estando en el corazón de la realidad, ya que las cosas son lo que son, pero también algo más. Esta percepción es existencial y no solo teórica, con lo que se mantiene la fusión de sujeto y objeto.

Por último, el lenguaje recupera su función articuladora de la realidad. En este punto, Izutsu recurre a la doctrina esotérica del monje budista Kukai, que "afirma que el estado resultante es, de hecho, expresable (kabun kasetsu), y admite el funcionamiento de una dimensión del lenguaje diferente con la habilidad de expresar la realidad misma" ${ }^{34}$. No se trata de un lenguaje diferente del ordinario, sino usado de modo diferente, como en los mantras: en él "puede expresarse la última verdad" 35 , porque el "fundamento o esencia de la existencia es ella misma lenguaje" ${ }^{36}$. Esta es la intuición subyacente a la kabbala judía.

En este sentido, la metáfora representa en Izutsu un papel realmente facilitador del contacto con el Ser, a diferencia de la metáfora absoluta blumenberguiana, que tiene el efecto opuesto.

En términos de la discusión sobre el Apocalipsis, Izutsu estaría en sintonía con la tradición de pensamiento católica, que ve en el fin del mundo la oportunidad para el segundo advenimiento del Mesías y la transfiguración de este mundo en otro mejor,

\footnotetext{
${ }^{32}$ T. Izutsu, Bewusstsein und Wesen, op. cit.

${ }^{33}$ Que, en este nivel, todo esté presente podría explicar fenómenos psíquicos como los sueños premonitorios o las coincidencias significativas (C. G. Jung, M.-L. von Franz, J. L. Henderson, J. Jacobi y A. Jaffé, op. cit., p. 66).

${ }^{34}$ S. Takagi, "Introduction, Kukai on the Philosophy of Language", en On Oriental Philosophy 5, 2010, Tokyo, Keio University Press, pp. 1-25, aquí p. 24.

${ }^{35}$ Ibidem, p. 21.

${ }^{36}$ Ibidem, pp. 14-15.
} 
pero sin perder su identidad. Esto es lo que acontece en el proceso de conocimiento, según Izutsu: destrucción del mundo y reconfiguración en su verdadera esencia.

\section{Conclusiones}

En conclusión, puede afirmarse que la de Blumenberg es una filosofía anti-apocalíptica, una forma extrema del cinismo: nunca pasa nada. Blumenberg fundamenta su postura en el predominio de lo corporal y mundano sobre lo ideal. Allí donde lo ideal y abstracto prevalece, el ser humano lleva las de perder, es sacrificado, él y su mundo, en aras de una entidad mayor, llámese Dios o el Ser. Antropología filosófica significa, para Blumenberg, que no puede haber verdadero Apocalipsis, sino siempre un mundo. Lo interesante del planteamiento de Izutsu y, según él, de ciertas tradiciones orientales de pensamiento, es que el acceso al Ser, a través de la contingencia, se realiza a través del cuerpo y lo mundano: imaginación, lenguaje, inconsciente, ejercicios rituales... Con ello, también Izutsu eleva la dignidad ontológica de la antropología por encima de la metafísica clásica y planteamientos contemporáneos como el de Heidegger. La dificultad de la propuesta de Izutsu radica en que es pragmática: hay que ejercitarla, llevarla a cabo, para comprobar su validez ontológica. Es, en ese sentido, también contingente en sí misma-lo cual, al mismo tiempo, es un argumento a su favor. 